\title{
IDENTIDADE AFRO-BRASILEIRA: ABORDAGEM DO ENSINO DA ARTE
}

\section{$O$ resgate da arte e dos padrões estéticos da produção negro-africana no ensino de Arte revigoram a formação da subjetividade e da identidade do estudante negro}

Pesquisas recentes têm apontado para a dificuldade de aceitação da identidade negro-africana por parte de enorme parcela do alunato de nosso país, ocasionando problemas de repetência, evasão escolar e impedindo o pleno exercício da cidadania por parte dos educandos ${ }^{1}$.

Livros didáticos de Educação Artística, adotados por $30 \%$ de professores da rede pública e consultados por $70 \%$ destes, são totalmente omissos no que se refere à produção cultural e artística do negro ${ }^{2}$.

Sabemos que a herança histórica brasileira tem dificultado às camadas subalternas vivenciarem suas experiências estéticas. Também a indústria cultural, juntamente com o sistema educacional, tem imposto padrões homogeneizantes, desvalorizando e negligenciando a heterogeneidade e a diversidade de nossa cultura, omitindo a presença partícipe dos descendentes de escravos.

A bibliografia disponível para o ensino da Arte é omissa no que se refere à arte

\section{A AUTORA}

\section{Dilma de Melo Silva}

Professora Doutora do Departamento de Comunicações e Artes da ECA. Especialista em Teoria e Crítica da Arte. Presidente da Comissão de Pesquisa da ECA-USP.E-mail: dilsil@usp.br africana e incompleta quanto à afro-brasileira. Os professores de educação artística se formam sem nunca terem tido sequer uma disciplina com conteúdos relativos à estética negra ou às raízes africanas. Tem-se, ainda, em nossa produção simbólica, o agravante da ideologia do embranquecimento e do mito da democracia racial imposta pelos setores hegemônicos da sociedade.

Desse modo, parece-nos oportuno trazer a discussão sobre Relações Étnicas e Relações Raciais, focalizando a arte e a estética africanas.

\section{ESTÉTICA AFRICANA}

Nosso interesse se volta para as raízes africanas da arte na arte brasileira atual. Quais elementos estão presentes, vindos pela mão dos africanos, no período Colonial e Imperial, e quais foram trazidos por via erudita, através de artistas brasileiros que foram à Europa e lá tiveram contato com a produção africana.

Desde o período Colonial, desenvolveu-se, em nosso país, uma cultura estética hegemônica e uma cultura estética subalterna (ou popular), produzidas pelas duas vertentes acima apontadas. No nível da produção hegemônica assistimos, no período

1. FUNARI, R. M. L. O ensino da Arte no Brasil em busca das raízes culturais africanas. São Paulo, ECA-USP. 1993. (Dissertação de Mestrado).

2. FERRAZ, H. T. Arte-Educação, vivência, experienciação ou livro didático? São Paulo: Loyola, 1987. 
colonial, à formação de uma iconografia católica ligada ao período pré-renascentista europeu e, no período republicano, à introdução das artes e dos padrões de beleza calcados nos cânones de beleza greco-romanos - um estudo do Barroco e da atuação da Missão Francesa seria ilustrativo para compreendermos o que ocorreu em nosso país.

O Barroco brasileiro mostrava um rompimento com os cânones estéticos europeus, tendo produzido obras originais de artistas vindos das camadas populares. Mas a Missão Francesa significou o retorno à ordem, com a imposição do neoclássico, levando a um retraimento da produção popular.

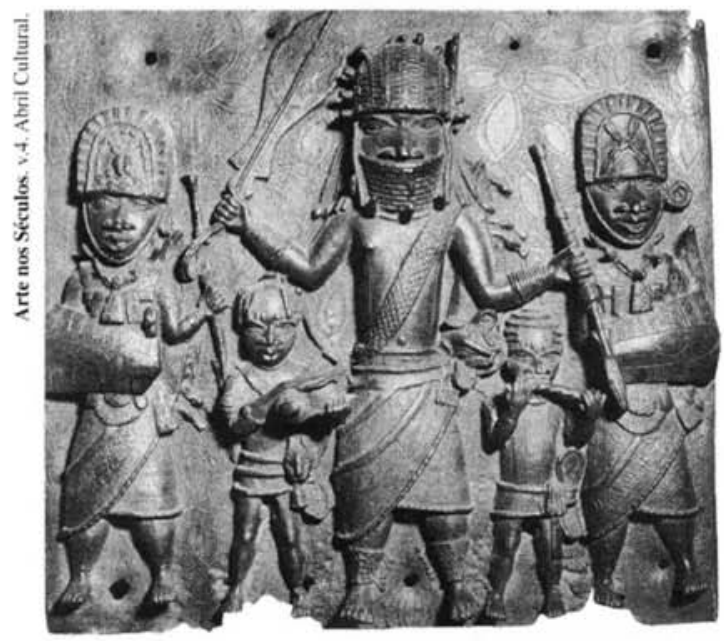

Do fundo decorado com motivos florais gravados destacase, em alto-relevo, a vigorosa figura de um soberano ladeado por guerreiros. (Arte Benin, lâmina em bronze, Nelson Gallery of Art, Kansas City, EUA).

No que se refere à estética da cultura popular, vamos encontrar um alto grau de mestiçagem, unindo padrões da produção pré-colombiana, da africana e do catolicismo popular, mesclado aos padrões naturalistas greco-romanos.

Poderíamos exemplificar com um olhar sobre a iconografia ligada aos rituais de umbanda (religiosidade popular que mes- cla catolicismo, kardecismo, com elementos africanos e ameríndios): percebemos que a expressão plástica dos ancestrais caboclos traduz uma concepção culta do que seria o nosso indígena. $\mathrm{O}$ índio, na iconografia da umbanda, não é o índio real, mas um personagem saído da literatura, dos livros de José de Alencar ou de Gonçalves Dias.

Quanto à produção africana poderíamos acrescentar: sua presença já era registrada na Europa desde o século XV, quando um filho de André Tiraqueau, protegido de Rabelais, reúne em Paris uma coleção de objetos exóticos, os fetiches noires. No século XVI são levadas peças em madeira, marfim e bronze de zonas banto, atual Angola, para a Europa. No século XVIII um musicólogo da corte de Brunswick reproduz peças em marfim em seu Theatrum Instrumentorum. Ainda nesse mesmo período, são levadas peças em ouro da Nigéria (como a máscara do Rei Ashanti Koffe Kalakalli) e outras em bronze.

No século XIX, a Europa é inundada com objetos de origem africana: as expedições científicas e etnográficas dirigem-se ao continente africano e trazem consigo centenas e milhares de objetos que formam os acervos dos Museus da Europa: joalheria, esculturas, máscaras, suportes, placas, portas, frontões etc.

Em 1897, uma expedição punitiva da Marinha inglesa vai ao Benin, destrói a comunidade e carrega como despojo de guerra toda a produção plástica encontrada. Num único carregamento são levadas mais de duas mil peças, provocando uma ruptura na produção local, que fica despojada de suas matrizes. O Obá Ovonramwen foi exilado e, somente em 1914, os ingleses permitiram o retorno de um novo Obá e a reconstrução dos locais sagrados. 
Nos primeiros anos deste século, Matisse, Braque, Vlaminck, Picasso descobrem $\mathrm{a}$ arte negra. Apolinaire publica um primeiro álbum francês dedicado à escultura africana; em seguida, Carl Einstein publica Negesplastik. Os alemães, ligados ao Die Bruck (movimento de Artes Plásticas desencadeado, na Alemanha, nas primeiras décadas deste século), ao afirmarem em seus catálogos a necessidade de se buscar o instinto, de se buscar as causas viscerais das emoções, substituem os rostos humanos por máscaras africanas. A tela Demoiselles d'Avignon de Picasso, de 1907, é ilustrativa: o artista substitui o rosto feminino por uma máscara. Em 1919 é publicada em Paris uma antologia negra e, na década seguinte, são feitas grandes exposições com peças africanas $\mathrm{e}$ da Oceania: em Marselha, em Vincennes e na Galeria Pigalle, no Pavilhão Marsan em Paris. Em 1935, o Museu de Arte Moderna de Nova York organiza uma primeira exposição de arte africana.

A conceituação de primitiva dada à arte africana está diretamente ligada à idéia de que a inferioridade técnica de uma civilização implica uma inferioridade artística. Tal afirmação tem seu início com Da Vinci em sua hierarquização das Artes, harmonizandoas com o nível técnico das comunidades que as produzem. Desse modo, a pintura seria a primeira das Artes e os negros, que se limitavam à escultura, seriam artistas inferiores.

Com Hegel, a apreciação estética da produção africana se complica ainda mais, uma vez que para ele os africanos não tinham sequer história. Ele definiu explicitamente essa posição em sua Filosofia da História, a qual contém afirmações como as que se seguem: "a África não é um continente histórico, ela não demonstra nem mudança nem desenvolvimento"(....) "Os povos negros são incapazes de se desenvolver e de receber uma educação. Eles sempre foram tal como vemos hoje" ${ }^{3}$.

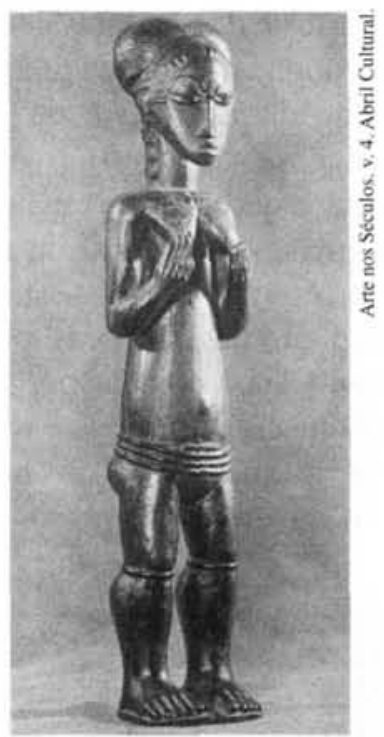

Formas estilizadas e rigidamente simétricas caracterizam esta figura humana em madeira. (Arte Guro, coleção particular, Milão, Itália).

Nessa linha de raciocínio entendemos a utilização dos adjetivos primitivo e arte primitiva. Quando os especialistas utilizam categorias estéticas européias, a produção africana aparece como distorcida, incapaz de elaborar obras nos moldes do europeu colonizador - assim, vemos que a estética sofreu a marca do positivismo e do funcionalismo do século XIX.

Contudo, a produção africana remonta de séculos antes da chegada dos europeus; as características formais da escultura africana: desproporcionalidade, exagero de uma ou outra parte, verticalidade, condizia com formas maciças, pesadas. $\mathrm{O}$ observador ocidental procurava captar o arranjo de volumes que não condizia com um arranjo de superfície e não a entendia. $\mathrm{O}$ encontro da arte européia com a arte africana é um ponto de intersecção na História da Arte 
bastante negligenciado pelos estudiosos $\mathrm{e}$ mereceria um estudo mais atento, para um melhor conhecimento de ambas.

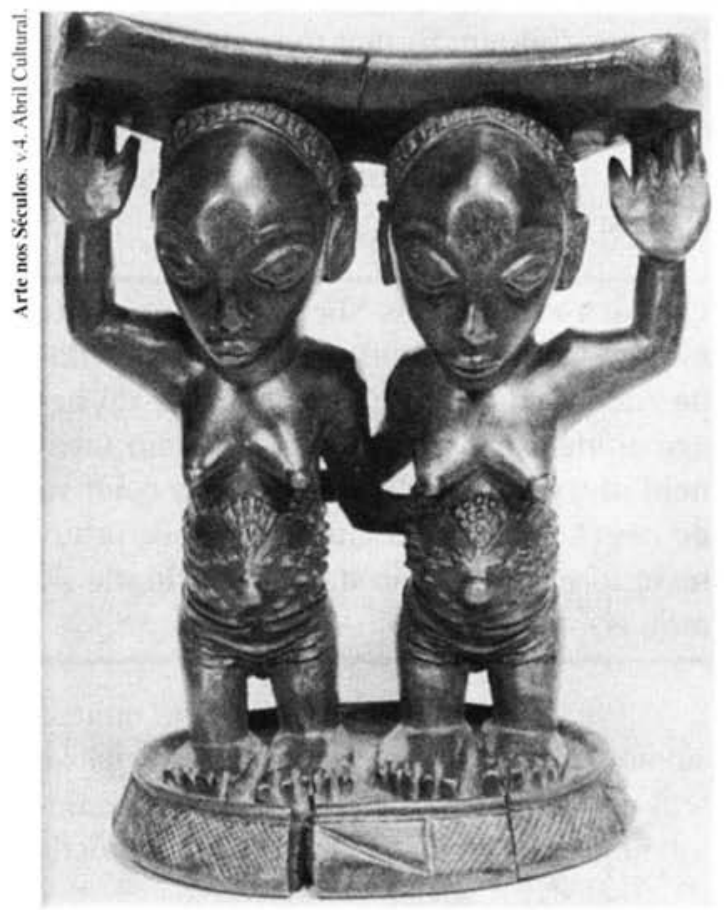

Um refinado grupo escultórico serve de base para a peça usada como apoio para cabeça. (Arte Baluba, Museu Britânico, Grã-Bretanha).

No Brasil, o artífice negro, para cá trazido pelo tráfico negreiro, vai atuar junto às Irmandades nas Igrejas, produzindo a iconografia católica do Barroco. Acreditamos que, também aqui, um estudo mais atento deveria voltar-se para o olhar e para as mãos dos artistas do período Colonial e Imperial.

Estudos mais recentes de Cunha, Araujo, Munanga ${ }^{4}$ nos mostram que a produção africana não se limitou a uma arte ritual mas ao que chamaríamos hoje de arte conceitual. Quando um artista quer representar a maternidade não está esculpindo uma mulher grávida, mas a idéia da fertili- dade, da gestação e, ao exagerar o ventre feminino, essa é a sua intenção.

A tese central da estética moderna centrada na produção euroamericana, afirmando que o artístico se realiza na obra de arte e que ela é autônoma, uma vez que o artista é um criador livre para se expressar, não encontra eco na produção africana.

Em comunidades africanas o artista se situa no centro de tensões dinâmicas, sua produção permeia a ordem e a desordem devido à sua capacidade de manipular forças vitais geradoras de transformações, destruição e aniquilação. Ele consegue fazer com que uma coisa (kintu) se transforme (kuntu) em beleza, em perfeição.

As categorias de análise da filosofia banto nos auxiliam a entender melhor a estética africana. Cunha, explicitando dados sobre a estética ioruba, nos aponta existência de 19 conceitos em ioruba para apreender a realidade estética. Dentre eles: jijora semelhança ao modelo, equilíbrio entre o modelo e a abstração da cópia; ifarahon visibilidade de como deveria ser o plano de trabalho; gigun - arranjo simétrico na escultura; odod - representação do indivíduo em pleno vigor; tatu - serenidade, compostura, harmonia.

As singularidades contidas na produção das culturas negro africanas não podem ser apreendidas através da ótica excludente ocidental, devido às funções diferenciadas desempenhadas pela arte comunicacional nessas sociedades. Tais funções seriam:

1. diferenciar o mundo dos homens, regido pela cultura, do mundo dos animais, regido pelos impulsos natos;

4. CUNHA, M. C. Apud ZANINI. História Geral da Arte no Brasil. São Paulo: W. M. Salles, 1983. ARAUJO, E. A mão afro-brasileira: significação da contribuição histórica e artística. São Paulo: Tenenge, 1988. MUNANGA, K. A propos de la fonction de l'art plastique en Afrique. Zaire: Afrique Noir, 1984. 
2. diferenciar uma comunidade das demais, dando-lhe uma identidade;

3. comprovar a luta dos homens para dominar a natureza, mas, também, afastarse dela, para alcançar o prazer infinito da criação.

\section{ARTE AFRO-BRASILEIRA}

Se formos traçar um breve esboço da presença do negro africano em nossa trajetória artística, verificamos que, devido à sua competência na escultura e na metalurgia, ocorreu "a presença de pardos e pretos nas obras de talho e douração das igrejas barrocas desde a metade do século XVI. O Barroco brasileiro mostra sua matriz africana em anjos e madonas com traços negróides; ou mesmo quando os temas e imagens negras escondem-se nas dobras dos mantos ou sob o peso do ouro da estatuária, como "otas em seus nichos" $"$.

Centenas de exemplos poderiam ser dados. A iconografia dos santos Cosme e Damião são reformulações dos Ibejis do Benin; a representação de Nossa Senhora da Conceição, ostentando cornos na cabeça e segurando emblema de Xangô, os oxês. Artistas negros e mestiços como Antônio Francisco Lisboa, Valentim da Fonseca e Silva e Francisco Chagas são representantes conhecidos do Barroco e têm registro na História da Arte brasileira. Mário de Andrade, ao analisar o Aleijadinho, nos fornece pistas para a compreensão da vertente africana escondida em nossa produção plástica.

Como afirmamos anteriormente, tais conhecimentos não são difundidos entre nós, nossa cultura omite essa herança. Os descendentes de escravos ignoram o valor da produção de seus antepassados, perma- necendo um desconhecimento sobre nossas raízes culturais e artísticas africanas. O sistema escolar não propicia aos indivíduos oriundos de tais grupos informações que lhes possibilitem formar uma auto-imagem, uma auto-representação positiva, que sirva de contra-ataque às investidas deterioradas feitas à identidade grupal e individual a que estão sujeitos estes grupos.

Embora as Ciências Sociais tenham feito muitos avanços, a cultura da inferioridade racial e o mito da primitividade do negro ainda estão presentes na contemporaneidade, penetrando na memória coletiva de negros e brancos em nosso país, interferindo na formação da subjetividade de ambos.

Por isso, o conhecimento da riqueza cultural e estética das sociedades africanas e seus desdobramentos na diáspora poderá contribuir para a eliminação dos estereótipos e da estigmatização social sofridas pelos negros. Tais estereótipos justificam a exploração e opressão pelo índice imaginário de superioridade de um grupo humano sobre outro.

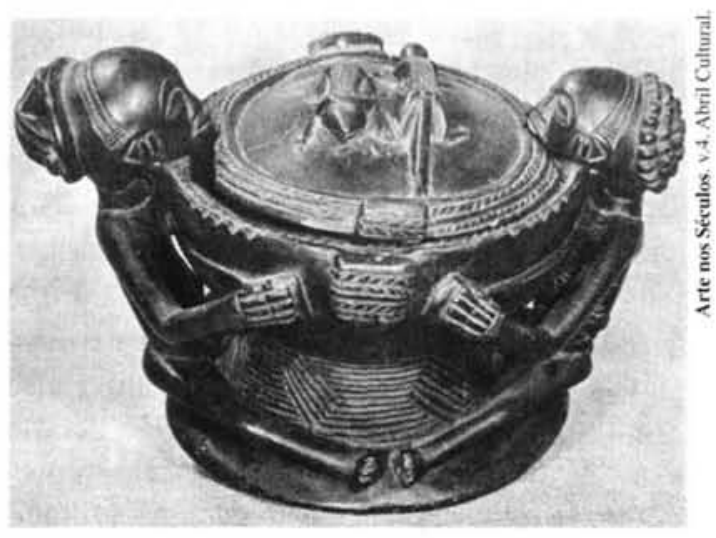

Taça com tampa, executada em madeira e ornamentada por duas figuras humanas esculpidas. (Arte Baluba, Museu da África Central, Tervuren). 
O nosso sistema educacional tem compactuado com a ideologia do embranquecimento com livros didáticos e práticas pedagógicas que omitem nossas raízes negro africanas, permitindo a difusão de valo-

Resumo: A omissão nos livros didáticos de Educação Artística de representaçōes da produção artístico-cultural do segmento negro e de sua tradição cultural tem contribuído para a permanência do preconceito e da marginalização do negro no Brasil. Resgatar a arte, a estética e a cultura negro-africana em seus diferentes aspectos e sua presença na cultura ocidental, principalmente brasileira, implica a valorização da identidade cultural do segmento negro.

Palavras-chave: Arte, Educação Artística, negro africano, cultura negra, marginalização res negativos com relação ao segmento negro. Devemos apontar, dentro do ensino da Arte, a valorização da identidade cultural de tal segmento.

Abstract: The article discusses how the omission, in Artistic Education didactic books, of representations of the artistic and cultural production of the black segment and of its cultural tradition, has contributed to the permanence of biases and to the marginalization of the black people in Brazil. The article proposes recovering the black-African art, aesthetics and culture in its different aspects and reinstating its presence in Western culture, most especially in the Brazilian culture, to value the black segment's cultural identity.

Keywords: Art, Artistic Education, black culture, marginalization 